\title{
Research on subsidy mechanism in the government-led agricultural supply chain finance
}

\author{
LU Qi hui ${ }^{1}$, Xu Tingting ${ }^{2 *}$ \\ ${ }^{1}$ School of Business Administration, Zhejiang Gongshang University Hangzhou, China \\ ${ }^{2}$ School of Business Administration, Zhejiang Gongshang University Hangzhou, China
}

\begin{abstract}
The problem of difficult and expensive financing of credit funds restricts the development of agriculture in our country. The government adopts different measures to support and guide the sustainable development of agriculture, there are typical loan interest subsidy mechanism. Under the background of agricultural output is uncertain, a supply chain system composed of farmer, company, bank and the government has been established, it discusses the government subsidy for agricultural supply chain operation and the influence of the members of the decision-making, explores the differences between two kinds of mechanism and provides suggestions for the decision of the supply chain members. Studies have shown that in the context of government subsidy, when the random output factor is higher and the loan interest rate is lower, the higher the loan interest subsidy rate, the higher the profit and social welfare of farmer, company, and bank. When the bank interest rate is higher than a certain value, the government subsidy can increase the profits of farmer and bank. Finally, numerical simulation found that in the context of government subsidy, government subsidy reduces the financing cost of farmer, but the real beneficiary is bank.
\end{abstract}

\section{Introduction}

Due to the particularity of agriculture, most of the farmers are facing with difficulties in financing. First, the agricultural risk is high, and the bank is not willing to lend; second, the farmers lack the collateral or pledge recognized by the bank, so it is difficult to apply the traditional financing mode; third, the loan process is long, the procedures are complex, the interest rate is high and many hidden costs. The difficulty and high cost of financing restrict the industrial upgrading and sustainable development of agriculture in China . For example, in 2019 , less than $25 \%$ of China pig breeding enterprises with 10000 heads of scale and above account for a general lack of mortgage financing Because of the difficulty in financing, enterprises are generally faced with the problem of insufficient liquidity.

At the same time, because agricultural production is affected by extreme weather, natural disasters and other uncontrollable factors, the degree of uncertainty of its output is high. For the lower reaches of the agricultural supply chain, when the output of farmers can not meet the demand, it will bring serious loss of profits. Farmers' income cannot cover the cost of inputs, which will lead to problems in the capital flow in the agricultural supply chain, China attaches great importance to the establishment of a government led and financial support mechanism for agricultural development. Government subsidy is an important way to provide agricultural business entities.
Government subsidy is the active management behavior to encourage industry development and support vulnerable groups, and to ensure national industrial security and stability, in recent years, the central government has continuously increased the financial budget of agricultural subsidy, and the local government has also built a corresponding discount mechanism. For example, in 2019, Hubei Province issued a new subsidy policy for the dairy farming industry. For each dairy farm, government gave subsidy and coordinated with the financial sector for a loan of 3 million yuan.

Based on the above practical problems, this paper will discuss the optimal decisions of company and farmer, as well as the profits of each member of the agricultural supply chain in the agricultural supply chain financial model of government subsidy under the environment of uncertain output, so as to provide theoretical reference for the decision-making of farmer, enterprise, bank and the government.

\section{JOURNALS REVIEWED}

The research related to this paper mainly includes three aspects: operation and management under uncertain output, agricultural supply chain finance, and agricultural supply chain under the guidance of government.

At present, many scholars pay attention to the research of operation management under uncertain output. The main research issues include production decision-making, coordination mechanism, etc, When the output is uncertain, suppliers can get higher income share or higher

\footnotetext{
*Corresponding author: 1556413172@qq.com
} 
wholesale price. Ye Fei et al. Considered the optimal decision-making strategy of farmers when the output is uncertain and constrained by funds. Cai et al. Found that commitment order contract can stimulate the production of suppliers under the condition of output uncertainty. Ding et al. At the same time, under the background of uncertain output, Huang Jianhui and Lin Qiang studied the four stage dynamic game problem among the government, bank, company and farmer.

With the advancement of agricultural modernization and the innovation of supply chain, the application of supply chain finance has alleviated the problem of agricultural financing to a certain extent. Some scholars began to study the problem of agricultural supply chain finance. On the one hand, it is the problem of financing decision-making and income distribution mechanism. Zhao et al. Compared the retailer prepayment discount mode and the buyer supported purchase order financing mode under the condition of capital constraints. Huang et al. Studied the effects of initial working capital and interest rate on the equilibrium order quantity and the overall performance of the supply chain under the mode of retailers obtaining short-term financing through supplier credit guarantee loan (CGL); Chen Yonghui et al. Constructed the pricing model of agricultural supply chain financial loan service, and put forward the pricing rules and production decision of agricultural supply chain finance loan service; Ye Fei and Cai Zigong found that after the implementation of the "two-way subsidy" price coordination mechanism, the company and farmers realized the goal of income sharing and risk sharing.

On the other hand, risk management in supply chain finance. Chen analyzed the impact of bank credit financing on risk averse suppliers' decision-making. Yan et al. Studied the comparison of loan and investment financing schemes provided by loss averse retailers under the condition of insufficient funds. Devalkar et al. Considered the moral hazard and financing cost of suppliers, In the aspect of agriculture, ye Fei pointed out that the contract mechanism of "B-S Option Pricing + production cooperation + margin" can help to reduce the market risk of the company; Wang Wenli and Guo $\mathrm{Na}$ considered the uncertainty of wholesale price of agricultural products, the possible default of the company and the moral hazard of farmers, and analyzed the decision-making of farmers; input of agricultural materials and the pricing strategy of the company.

For the study of government subsidy, Ye Fei and Lin Qiang pointed out that when the government subsidizes farmers who participate in order production, it should pay special attention to the pricing method and subsidy method. Chen Jun and others analyzed the Optimal Subsidy proportion of the government by establishing a sequential game model between the government and members of the agricultural supply chain, Huang Jianhui et al. Constructed a three-stage game model of government, retailers and agricultural enterprises, and discussed the impact of government subsidy on the interests of all parties in the supply chain. Yu Xing et al. Established a three-stage Stackelberg game model of farmers, company and the government under different purchase prices with government subsidy, This paper analyzes the impact of government subsidy rate on the interests of farmers, company and social welfare. Zhang Wuxian and Wang Shaofeng discuss the impact of different contracts on product greenness and supply chain performance under the uncertainty of government subsidy and output.

To sum up, the existing literature on output uncertainty mainly focuses on the supply chain operation, less on the problem of capital constraints. At the same time, although there are many studies on agricultural supply chain finance, most of the literature mainly discusses the problems of performance, management risk, financing and income in supply chain finance, In addition, most of the literatures on government subsidy use empirical research method to describe the concept and value qualitatively, and the research on the management mechanism of government subsidy using modeling method is rare.

Therefore, this paper will use the modeling method to study the subsidy mechanism in the government led agricultural supply chain finance under the background of uncertain output, so as to provide decision-making reference for supply chain members, On the other hand, this paper uses quantitative analysis to study the government led risk management mechanism, and theoretically analyzes the value of government subsidy to the whole agricultural supply chain and its members, This paper explores the effects of government subsidy on the income of supply chain members, provides a reference for the government and bank to choose strategies, and supplements and develops the existing government led risk management theory.

\section{3 model description and hypothesis}

This paper considers a single cycle two-level supply chain model composed of farmer, core enterprises (hereinafter referred to as the company), bank and the government. It is assumed that before production, farmer have no initial capital and need to borrow money from the bank. The loan interest rate is $r_{i}(i=1)$, and the operation of the company is not constrained by capital. It is assumed that the production cost (q) of farmer is related to the production input $q$, which is consistent with that of Ye Fei et al. And Niu et al. This article assumes that the production cost function of farmer is $C(q)=c_{1} q+$ $\frac{c_{2}}{2} q^{2}$. Where $\left(c_{1}>0\right)$ represents the production cost of agricultural products, such as the purchase of seeds, chemical fertilizers, pesticides and other agricultural means of production, and $\left(c_{2}>0\right)$ represents the effort cost coefficient of farmer in the production process of agricultural products. It refers to the effort cost of farmer to produce agricultural products, including the time, energy, technology investment, etc.

The actual output of agricultural products is affected by natural factors, and there is uncertainty. It is recorded as the random output factor of agricultural products, that is, the output obtained by the unit production input of agricultural products. This paper assumes that it follows two-point distribution. When the agricultural production is normal, the farmer will not default. At this time, the 
random output factor $x=x_{0}$, and the probability is $\varphi$, where $\varphi \in[0,1]$ When the production of agricultural products is affected by adverse conditions, the purchase money paid by the company to the farmer may not be enough to repay the loan principal and interest of the bank, then the farmer may default. At this time, the random output factor of agricultural products $x=\theta x_{0}, \theta \in[0,1]$, and the probability is $\bar{\varphi}=1-\varphi$.

When a company purchases all the agricultural products produced by farmer, it is assumed that the company only considers the acquisition cost of agricultural products, does not consider the residual value of agricultural products, and the acquisition volume (sales volume) is equal to the output volume $q x$, and sells them at the same priceq $p . \Pi_{F i}, \Theta_{E i}, \Omega_{B i}, S W_{i}$ represent the expected profits and total social welfare of farmer, company and bank respectively, $i=0$ represents the situation without government participation, $i=1$ represents the situation in which the government adopts loan interest subsidy.

\section{Research on the government subsidiy}

In the case that the government provides loan interest subsidy to farmer, the agricultural supply chain includes four participants: company, farmer, government and bank.

1) The government provides a loan interest subsidy mechanism with a subsidy rate of $s(s \in[0,1])$, the bank gives the loan interest rate according to the subsidy rate $r_{1}$, and the company decides the price of agricultural products $w_{1}$ (the decision variable of the company) according to $S$ and $r_{1}$.

2) At the same time, according to the demand of production funds, the farmer apply to the bank and obtain loans $L\left(q_{1}\right)$ to meet $L\left(q_{1}\right)=C\left(q_{1}\right)$. The farmer put into production $q_{1}$ and pay production costs $C(q)=c_{1} q+$ $\frac{c_{2}}{2} q^{2}$.

3) The output of agricultural products $q_{1} x$ obtained by farmer is that the company purchases all the agricultural products produced by farmer and pays farmer for the purchase of agricultural products $w_{1} q_{1} x$.

4) Farmer use the purchase money of agricultural products $w_{1} q_{1} x$ to repay the loan. (1) if the purchase money of agricultural products is enough to repay the loan, the bank loan $\left(1+(1-s) r_{0}\right) L\left(q_{1}\right)$ (sum of principal and interest) will be paid off, and the remaining part $\left(w_{1} q_{1} x-\left(1+(1-s) r_{0}\right) L\left(q_{1}\right)\right)$ will be owned by farmer; (2) if not, farmer will default, and the outstanding debt $\left(\left(1+(1-s) r_{0}\right) L\left(q_{1}\right)-w_{1} q_{1} x\right)$ will be borne by the bank, The government discount $s L\left(q_{1}\right)$ is paid directly to the bank.

5) The company sells the purchased agricultural products to the market at the selling price $p$, and obtains the sales payment $\mathrm{p} q_{1} x$.From the above, we can see that the profit function of farmer is: $\pi_{F 1}\left(q_{1}\right)=w_{1} q_{1} x-$ $\left(1+(1-s) r_{0}\right)\left(c_{1} q_{1}+\frac{c_{2}}{2}\left(q_{1}\right)^{2}\right)$. Consistent with the reality, This paper assumes that the farmer is a bounded rational decision maker, It takes the maximum expected profit as the goal to make production decision, In the case of low output, there is the possibility of default. meanwhile, Consistent with the reality, It is assumed that the interest rate of the loan offered by the bank will not be extremely high, which is $r_{1} \leq \frac{p \varphi x_{0}-c_{1}}{c_{1}(1-s)}$. Otherwise, the farmer will breach the contract.

Since the company makes decisions with the goal of maximizing profit, the purchase price should be $w_{1} \leq p$, and the expected profit function is as follows:

$$
\begin{aligned}
& E\left(\Theta_{E 1}\left(w_{1}\right)\right)=E\left(\left(p-w_{1}\right) q_{1} x\right) \\
& \quad=x_{0}(\varphi+(1-\varphi) \theta)\left(p-w_{1}\right) q_{1}
\end{aligned}
$$

Proposition 1 1) in the agricultural supply chain financial model under the situation of government subsidy, the decision-making equilibrium $\left(w_{1}^{*}, q_{1}^{*}\right)$, between company and farmer can be expressed as

$$
\begin{gathered}
w_{1}^{*}=\frac{p x_{0}(\varphi+(1-\varphi) \theta)+c_{1}\left(1+(1-s) r_{0}\right)}{2 x_{0}(\varphi+(1-\varphi) \theta)}, \\
q_{1}^{*}=\frac{p x_{0}(\varphi+(1-\varphi) \theta)-c_{1}\left(1+(1-s) r_{0}\right)}{2 c_{2}\left(1+(1-s) r_{0}\right)} .
\end{gathered}
$$

There is a unique $\theta_{1}^{*}$ meet the following equation makes the expected profit function zero:

$$
\begin{gathered}
w_{1}^{*}\left(\theta_{1}^{*}\right) q_{1}^{*}\left(\theta_{1}^{*}\right) x_{0} \theta_{1}^{*} \\
=\left(1+(1-s) r_{0}\right)\left(c_{1} q_{1}^{*}\left(\theta_{1}^{*}\right)+\frac{c_{2}}{2}\left(q_{1}^{*}\left(\theta_{1}^{*}\right)\right)^{2}\right)
\end{gathered}
$$

Whens $=0$, it is a special case without government participation. From proposition 1 1), we can see that the decision-making equilibrium between the company and farmer is $\left(w_{0}^{*}, q_{0}^{*}\right)$ :

$$
\begin{aligned}
& w_{0}^{*}=\frac{p x_{0}(\varphi+(1-\varphi) \theta)+c_{1}\left(1+r_{0}\right)}{2 x_{0}(\varphi+(1-\varphi) \theta)}, \\
& q_{0}^{*}=\frac{p x_{0}(\varphi+(1-\varphi) \theta)-c_{1}\left(1+r_{0}\right)}{2 c_{2}\left(1+r_{0}\right)} .
\end{aligned}
$$

Proposition 12 ) shows that there exists a unique $\theta_{1}^{*}$ when $\theta>\theta_{1}^{*}$, the expected income of farmer and bank are as follows:

$$
\begin{array}{r}
\pi_{F 1}^{*}=x_{0}(\varphi+(1-\varphi) \theta) w_{1}^{*} q_{1}^{*} \\
-\left(1+(1-s) r_{0}\right)\left(c_{1} q_{1}^{*}+\frac{c_{2}}{2}\left(q_{1}^{*}\right)^{2}\right), \\
\Omega_{B 1}^{*}=r_{0}\left(c_{1} q_{1}^{*}+\frac{c_{2}}{2}\left(q_{1}^{*}\right)^{2}\right),
\end{array}
$$

When $\theta<\theta_{1}^{*}$, the expected income of the farmer and the bank is:

$$
\begin{gathered}
\pi_{F 1}^{*}=\varphi\left(w_{1}^{*} q_{1}^{*} x_{0}-\left(1+(1-s) r_{0}\right)\left(c_{1} q_{1}^{*}+\right.\right. \\
\left.\left.\frac{c_{2}}{2}\left(q_{1}^{*}\right)^{2}\right)\right), \\
\Omega_{B 1}^{*}=\varphi\left(1+r_{0}\right) \\
+(1-\varphi) s r_{0}-1\left(c_{1} q_{1}^{*}+\frac{c_{2}}{2}\left(q_{1}^{*}\right)^{2}\right)+(1- \\
\varphi) w_{1}^{*} q_{1}^{*} \theta x_{0} .
\end{gathered}
$$

When $s=0$, In special cases where there is no government involvement, Existence threshold $\theta_{0}^{*}$, the relevant profit of each member of the supply chain $\Pi_{F 0}, \Theta_{E 0}, \Omega_{B 0}$. The related expressions are omitted here. 
Because the funds subsidized by the government belong to the public resources of the society, the government must proceed from the overall interests of the society to achieve the optimization of social welfare. Social welfare is composed of producer surplus and consumer surplus, that is, it is composed of the interests of all parties in the agricultural supply chain (farmer \& company \& bank \& government \& consumers), and subtract the government subsidy funds. Farmer, company and bank are business entities, so the expected profits of the three represent their respective interests. The government measures their expenditures by actual subsidy, and the government expenditures are expressed by $\mathrm{H}_{i}$ $(i=1,2)$. Consumers measure their interests by consumer surplus. Because this paper assumes that the market price is fixed, the consumer surplus is zero, that is to say $C S=$ 0 . According to the above analysis, the social welfare function is as follows:

$$
\begin{aligned}
& S W_{1}=E\left[\pi_{F 1}\left(q_{1}\right)+\Theta_{E 1}\left(w_{1}\right)+\Omega_{B 1}+C S_{1}-\right. \\
& \left.s r_{0}\left(c_{1} q_{1}+\frac{c_{2}}{2}\left(q_{1}\right)^{2}\right)\right]
\end{aligned}
$$

The expected profit function of each party is substituted into the above formula, The optimal social welfare function is:

$$
S W_{1}^{*}=p x_{0}(\varphi+(1-\varphi) \theta) q_{1}^{*}-\left(c_{1} q_{1}^{*}+\frac{c_{2}}{2}\left(q_{1}^{*}\right)^{2}\right)
$$

Proposition 2 In the context of government subsidy, On the properties of the optimal solution:
1) $\frac{d w_{1}^{*}}{d \varphi}<0, \frac{d w_{1}^{*}}{d \theta}<0, \frac{d w_{1}^{*}}{d r_{0}}>0, \frac{d w_{1}^{*}}{d s}<0$.
2) $\frac{d q_{1}^{*}}{d \varphi}>0, \frac{d q_{1}^{*}}{d \theta}>0, \frac{d q_{1}^{*}}{d r_{0}}<0, \frac{d q_{1}^{*}}{d s}>0$.

The price of agricultural products purchased $w_{1}$ by the company decreases in $\varphi$, increases in $\theta$, and the production input $q_{1}$ of farmer increases in $\varphi$ and $\theta$, decreases in $r_{1}$. So for the company, with the increase of the loan interest subsidy rate, the company will reduce the purchase price. Therefore, the production input increases with the loan interest subsidy rate, and the purchase price decreases with the loan interest subsidy rate.

Proposition 3 In the case of government subsidy, the optimal profits of farmer, company and bank have the following properties.

$$
\text { 1) if } \theta>\theta_{1}^{*}, \frac{d \pi_{F 1}^{*}}{d \theta}>0, \frac{d \pi_{F 1}^{*}}{d \varphi}>0, \frac{d \pi_{F 1}^{*}}{d r_{0}}<0, \frac{d \pi_{F 1}^{*}}{d s}>
$$

0 .

2) $\frac{d \Theta_{E 1}^{*}}{d \theta}>0$; if $r_{1}<\frac{p \theta x_{0}-c_{1}}{c_{1}(1-s)}, \frac{d \Theta_{E 1}^{*}}{d \varphi}>0$; when $c_{1}<$ $\min \left(\frac{p x_{0}(\varphi+(1-\varphi) \theta)}{2-s}, p \varphi x_{0}, p \theta x_{0}\right), \frac{d \Theta_{E 1}^{*}}{d r_{1}}<0$. When $r_{1}<$ $\frac{p x_{0}(\varphi+(1-\varphi) \theta)-c_{1}}{c_{1}}, \frac{d \Theta_{E 1}^{*}}{d s}>0$.

3) If $\theta>\theta_{1}^{*}, \frac{d \Omega_{B 1}^{*}}{d \theta}>0, \frac{d \Omega_{B 1}^{*}}{d \varphi}>0, \frac{d \Omega_{B 1}^{*}}{d s}>0$.

Proposition 3 1) shows that in the case of government subsidy, when the $\theta$ is greater than the threshold value of farmer bankruptcy $\theta_{1}^{*}$, the profit of farmer increases in $\varphi, s$ and $\theta$, decreases in $r_{1}$. For farmer, higher normal production probability, smaller change of random output factor, higher subsidy rate and lower bank interest rate can increase their income.

Proposition 3 2) shows that when the loan interest rate $r_{1}$ is in the feasible range, high probability of normal production and small change of random output factor will increase the profit of the company. When the input cost coefficient of farmer $c_{1}$ is less than a certain value, the profit of the company decreases monotonously with the loan interest rate $r_{1}$, and the bank loan interest rate has a reverse relationship with the company profit. Company profit increases monotonously with loan interest subsidy rate.

Proposition 3 3) shows that when $\theta>\theta_{1}^{*}$, The profit of bank increases in $\varphi$ and $\theta$, and has a positive relationship with subsidy rate $s$.

Proposition 4 In the case of government subsidy, the effects of $\varphi 、 \theta 、 r_{1} 、 s$ on social welfare are as follows:

1) When $c_{1}<\bar{c}_{1}, \frac{d S W_{1}^{*}}{d \theta}>0$.

2) When $c_{1}<\tilde{c}_{1}, \frac{d S W_{1}^{*}}{d \varphi}>0$.

3) $\frac{d S W_{1}^{*}}{d r_{0}}<0, \frac{d s W_{1}^{*}}{d s}>0$.

Among them, $\bar{c}_{1}=\frac{p \varphi x_{0}\left(3+4(1-s) r_{0}\right)}{\left(1+(1-s) r_{0}\right)\left(3+2(1-s) r_{0}\right)}$,

$\tilde{c}_{1}=\frac{p \theta x_{0}\left(3+4(1-s) r_{0}\right)}{\left(1+(1-s) r_{0}\right)\left(3+2(1-s) r_{0}\right)}$.

When the input cost coefficient of farmer $c_{1}$ is less than a certain value, the social welfare function increases with the increase of loan interest subsidy rate $S$, and the increase of loan interest subsidy rate is beneficial to the whole society.

Proposition 5 If $r_{0}=r_{1}<\frac{p \varphi x_{0}-c_{1}}{c_{1}}$. To compare the profits of farmer and bank under the situation of nongovernment participation and government subsidy, the results are as follows:

When $\theta>\max \left(\theta_{0}^{*}, \theta_{1}^{*}\right), \Pi_{F 1}^{*}>\Pi_{F 0}^{*}, \Omega_{B 1}^{*}>\Omega_{B 0}^{*}$.

If the loan interest rate is less than a certain value, $\theta$ is large, in the case of non-government participation and government subsidy, the profit of farmer and bank in the case of government subsidy is higher than that of farmer and bank in the case of non-government participation. In the case of government subsidy, the interest rate of farmer loans from bank is reduced, the production cost of farmer is reduced, and the burden of farmer is reduced, Finally, it improves the profit of farmer and the income of bank.

\section{Numerical analysis}

Due to the uncertainty of agricultural production, bank face higher risks when providing financing to farmer. In the case of government subsidy, the relationship between bank profits and normal production probability $\varphi$ and random output $\theta$ is considered. The relevant parameters 
in the supply chain are $x_{0}=5, c_{1}=0.6, c_{2}=0.3, p=$ $1, s=0.1$.

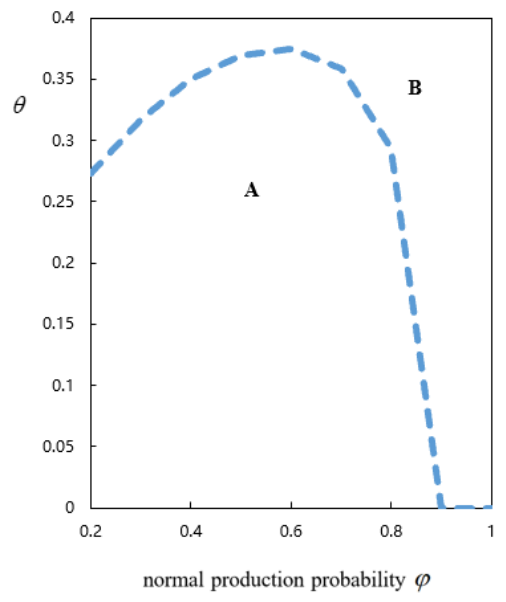

Figure 1. the change of bank profit under the situation of government subsidy.

The dotted line in Figure 1 indicates the parameter value when the bank profit is zero, that is $\Omega_{B 1}^{*}=0$, the bank profit in region $\mathrm{A}$ is less than zero, and the bank profit in region $\mathrm{B}$ is greater than zero. Figure 1 shows that when the probability of normal production of agricultural production is low ( $\varphi$ is small), the bank profit in region a is less than zero, only when the agricultural production is affected by adverse conditions and the output rate is relatively high ( $\theta$ is large), the bank can profit from the agricultural loan, otherwise it will bear the loss.

When the probability of normal production of agricultural production is high ( $\varphi$ is large), even if the output rate is $\operatorname{low}(\theta$ is small), Bank can always profit from agricultural loans. Therefore, bank should focus on the probability of normal agricultural production when carrying out agricultural loans, which can better reduce loan losses.

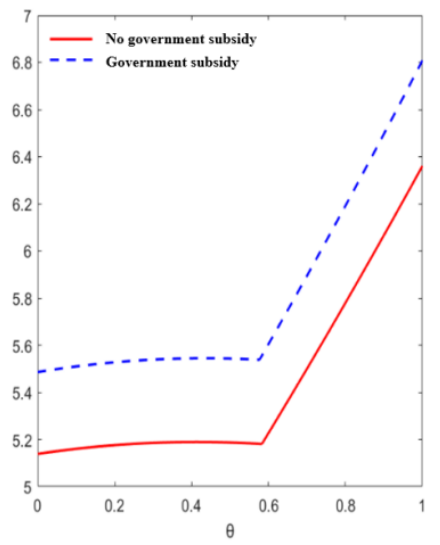

Figure 2. comparison of farmer profits under the circumstances of no government participation and government subsidy

Through certain numerical research, we compare the profit of farmer in the context of government subsidy and no government participation. It is found that the profit of farmer in the context of government subsidies is always higher than the profit of farmer in the context of no government participation. The relevant parameters in the supply chain are $x_{0}=5, c_{1}=0.6, c_{2}=0.3, p=1, s=$ 0.3 .

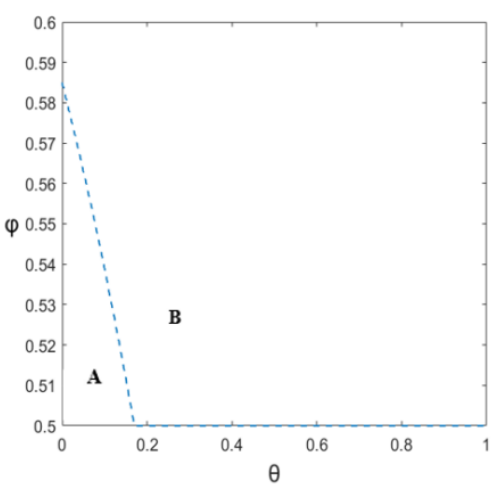

Figure 3. comparison of company profit under the circumstances of no government participation and government subsidies

We compare the company profit in the context of government subsidies and the company's profit in the context of no government participation. All points on the dotted line satisfy that the company's profits in the two scenarios are equal. Region A indicates that the company's profit is higher in the context of no government participation, and Region B indicates that the company's profit is higher in the context of government subsidies.

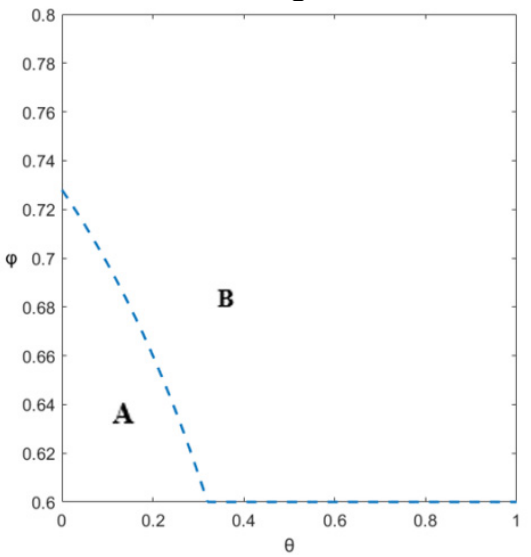

Figure 4. comparison of social welfare under the circumstances of no government participation and government subsidies

A comparison of social welfare under the two scenarios of government subsidies and no government participation is made. All points on the dotted line satisfy that the social welfare in the two situations is equal. Area A indicates that there are more social benefits in the context of no government participation, and area B indicates that more social benefits are obtained in the context of government subsidies. The relevant parameters in the supply chain are $x_{0}=3, r_{0}=3, c_{1}=0.6, c_{2}=$ $0.3, p=2, s=0.3$.

By studying the agricultural supply chain under the situation of government subsidy, the following conclusions are drawn:

First of all, when the probability of normal production increases, the random output factor increases and the loan 
interest rate decreases, the company will reduce the price of purchasing agricultural products, and the farmer will increase the production input accordingly. When the bank loan interest rate is small, the higher probability of normal production and the higher random output factor are beneficial to the farmer, and for the bank, the higher probability of normal production and the higher random output factor are beneficial to the farmer, Higher normal production probability and higher random output factor can increase its income.

Secondly, when the bank loan interest rate is small, the probability of normal production and the random output factor increase and the bank loan interest rate decreases, which will increase the company profit. When the input cost coefficient of farmer is small, higher normal production probability, higher random output factor and lower bank loan interest rate are beneficial to the whole society.

Finally, when the bank loan interest rate is small, with the increase of loan interest subsidy rate, farmer, bank and company get more profits. When the input cost coefficient of farmer is small, the higher the loan interest subsidy rate is, which is more beneficial to the whole society.

\section{Conclusion and significance}

This paper mainly analyzes the financial model of agricultural supply chain under the government subsidy.

First of all, under government subsidy the higher the normal production probability and random output factor, the higher the production input of farmer and the lower the price of agricultural products purchased by company, The higher the probability of normal production and the lower the loan interest rate, the higher the probability of normal production and the lower the stochastic output factor, the higher the profit of farmer and company, and the higher the probability of normal production and the stochastic output factor, the higher the profit of bank and social welfare.

Secondly, in the case of government subsidy, high interest subsidy rate will increase the production input of farmer and reduce the price of agricultural products purchased by company. High loan interest subsidy rate is beneficial to farmer, company, bank and social welfare. Low bank loan interest rate will improve social welfare.

Based on the financial model of agricultural supply chain with government subsidy, this paper provides the following enlightenment for farmer and enterprises: first, all participants in the agricultural supply chain should pay attention to the probability and random output factors of normal production. Secondly, we should pay attention to the differences between government subsidy, correctly treat the government led risk management mechanism, set reasonable and appropriate loan interest subsidy rate. This paper only considers the two-level supply chain composed of one farmer and one company. In the future, we can study the situation that there are multiple farmer or company in the supply chain and analyze the decisionmaking of members of the agricultural supply chain. In addition, this paper only takes government subsidy as one factor that affects the decision-making of members of the agricultural supply chain. In the future, the government can be considered as the main decision-makers in the supply chain.

\section{Acknowledgment}

This research was substantially supported by research grants from the National Natural Science Foundation of China (71672179).

\section{References}

1. Benyong Hu, Yi Feng. Hu B , Feng Y . Optimization and coordination of supply chain with revenue sharing contracts and service requirement under supply and demand uncertainty[J]. International Journal of Production Economics, 2017, 183(PT.A):185-193.

2. Ye F, Huang J H, Lin Q. The optimal production strategies of the farmer in contract-farming supply chain under capital constraint[J].Systems Engineering-Theory and Practice,2017,37(06):14671478.

3. Cai J H, Hu X Q, Jiang F Y, Zhou Q, Zhang X Y,Xuan L Y. Optimal input quantity decisions considering commitment order contracts under yield uncertainty[J]. International Journal of Production Economics, 2019, 216:398-412.

4. Ding W, Wan G H. Financing and coordinating the supply chain with a capital-constrained supplier under yield uncertainty $[\mathrm{J}]$. International Journal of Production Economics, 2020, 230:64-76.

5. Huang J H, Lin Q. Government subsidy mechanism in contract-farming supply chain financing under loan guarantee insurance and yield uncertainty $[\mathrm{J}]$. Chinese Journal of Management Science,2019,27(03):53-65.

6. Lima Zhao,Arnd Huchzermeier. Zhao L , Huchzermeier A . Managing supplier financial distress with advance payment discount and purchase order financing[J]. Omega, 2019, 88(Oct.):77-90.

7. Jing Huang, Wensheng Yang, Yiliu Tu. Huang J , Yang W, Tu Y . Supplier credit guarantee loan in supply chain with financial constraint and bargaining[J]. International Journal of Production Research, 2019:116.

8. Huang $\mathrm{J} \mathrm{H}$, Ye F, Lin Q. Government subsidy mechanism in agricultural supply chain considering capital constrain under random yield[J]. Chinese Journal of Management,2017,14(02):277-285.

9. Chen $\mathrm{Y} \mathrm{H}, \mathrm{Tu} \mathrm{H} \mathrm{Y}$, Zeng Y. Loan pricing and production adjustment mechanism in agricultural supply chain finance[J].Systems Engineering-Theory and Practice,2018,38(07):1706-1716.

10. Ye F, Cai Z G. Research on "Company + Farmer" Contract Farming Supply Chain Decision Model with Two Way Compensation Mechanism[J].Operations Research and Management Science,2018,27(05):186193. 
11. Jianxin Chen, Gabriella Bretti. Jianxin C . The Optimal Strategies of Risk-Averse Newsvendor Model for a Dyadic Supply Chain with Financing Service[J]. Discrete Dynamics in Nature and Society,2017,(2017-02-28), 2017, 2017:1-15.

12. Yan $\mathrm{N}$, Jin $\mathrm{X}$, Zhong $\mathrm{H}$, et al. Loss-averse Retailers\&apos; Financial Offerings to Capitalconstrained Suppliers: Loan vs. Investment[J]. International Journal of Production Economics, 2020, 227:107665.

13. Devalkar S K , Krishnan H . The Impact of Working Capital Financing Costs on the Efficiency of Trade Credit[J]. Production and Operations Management, 2018, 28.

14. Ye F, Lin Q, Mo R Q. Contract-farming supply chain coordination mechanism based on B-S model[J]. Journal of Management Sciences in China, 2012,15(01):66-76.

15. Wang W L,Guo N.Financing Strategies for Contract Farming Supply Chain Considering Moral Hazard[J].Journal of Systems and Management,2020, 29(01):128-134.

16. Ye F, Lin Q. Pricing model for contract-farming under sale price affected by yield[J]. Journal of Systems Engineering,2015,30(3):417-430.

17. Chen J, Zhang M, Cao Q H. Revenue-sharing contract of agri-food supply chain under brand promotion subsidy[J]. Industrial Engineering Journal,2016, 19(03):1-6.

18. Yu X, Zhang W G, Liu Y J. A coordinate mechanism of contract-farming based on relative floating price and government subsidies[J/OL]. Journal of Industrial Engineering/Engineering Management,2020:134-140.

19. Zhang S X, Wang S F. Contracts analysis of green supply chain: with a consideration of government subsidies and yield uncertainty[J].Ecological Economy,2020,36(11):66-74.

20. Niu B, Jin D, Pu X. Coordination of channel members\&apos; efforts and utilities in contract farming operations [J]. European Journal of Operational Research, 2016, 255(3):869-883.

21. Huang B , Wu A, Chiang D . Supporting small suppliers through buyer-backed purchase order financing $[\mathrm{J}]$. International Journal of Production Research, 2018, 56(17-18):1-24. 